\title{
ROCK SLIDE MONITORING BY USING TDR INCLINOMETERS
}

\author{
Marián DRUSA ${ }^{1,{ }^{*},}$ Roman BULKO ${ }^{1}$ \\ ${ }^{1}$ Department of Geotechnics, Faculty of Civil Engineering, University of Žilina, Univerzitná 8215/1, \\ 01026 Žilina, Slovakia. \\ corresponding author: marian.drusa@fstav.uniza.sk.
}

\section{Abstract}

The geotechnical monitoring of the slope deformations is widespread at present time. In many geological localities and civil engineering construction areas, monitoring is a unique tool for controlling of negative factors and processes, also inform us about actual state of rock environment or interacting structures. It is necessary for risk assessment. In our case, geotechnical monitoring is controlling rockslide activity around in the future part of motorway. The construction of new highway route D1 from Bratislava to Košice crosses the territory which is affected by a massive rockslide close to Kral'ovany village. There was a need to monitor the activity of a large unstable rockslide with deep shear planes. In this case of underground movement activity, the Department of Geotechnics of the University of Žilina installed inclinometers at the unstable area which worked on Time Domain Reflectometry (TDR) principle. Based on provided measurements, effectivity and suitability of TDR inclinometers for monitoring of deep underground movement activity is demonstrated.
\end{abstract}

\section{Keywords:}

Time domain reflectometry; Rock slide; Geohazard; TDR inclinometry; Slope deformation.

\section{Introduction}

To complete motorway route from west to east part of Slovakia, complicated terrain morphology of core mountains Malá Fatra, Vel'ká Fatra, and Choč nappe must be overpassed. In the territory of Kral'ovany village is situated water dam, route of first class, and railway line in one narrow valley. Beside of valley has been surveyed a massive rockslide near Sútovo village. This rockslide has been reactivated in the area of rock material exploitation in April 2013. The National Highway Company (NDS) as a contractor of civil works for highway ordered monitoring of slope deformations by mechanical inclinometers of classical technology and also inclinometer of Time Domain Reflectometry (TDR) technology [1, 2], supplemented by ground water level measurement by piezometers. Department of Geotechnics of University of Žilina installed vertical TDR inclinometers for underground movement monitoring. The aluminium copper coaxial cable CommScope has been fitted to $50 \mathrm{~m}$ deep borehole in February 2014 and injected with grout around of composition cement: bentonite: water in ratio $1.6: 1: 0.18$. From the first initiated measurements 6 stages of monitoring were done and results are demonstrated ability of this technology to monitor underground slope deformations.

\section{TDR and other new technologies}

There are several technologies in measurements of underground movements; Time Domain Reflectometry is one of many developments. Every of them have some advantages and also disadvantages. Better precision can be reached by installation of optical cables to boreholes, but this technology is expensive for measuring apparatus and it is suitable for very precise monitoring, [3]. Another newest development is system MUMS - Modular Underground Monitoring System [4], which operates on continuous and automated data acquisition. MUMS inclinometer is suitable to monitor the deformation of natural slopes or earth structures [5]. Inclinometer consists of nodes located at known distances along a connecting rope and can be installed in any directions - vertical, horizontal or inclined. The principle of measurement is in independent node location measures, its local rotation 
relative to the vertical/horizontal axis by means of a 3D micro electro-mechanical acceleration sensor (MEMS). The direction cosines of each node are calculated in order to determine the 3D shape and deformation of the entire borehole [4].

Demand for automatic and remote sensing monitoring systems for collecting of required geotechnical data, especially subsurface deformation and water pressure initiated competition between electric based techniques over the past 15 years. TDR technology is a technology that has been implemented for a variety of uses in electrical engineering. Since the 1930s, TDR has been used for examining electrical properties of cables and transmission lines, and measuring electrical properties of organic liquids. Universality and further enhancement of the technology during the '90s led to monitoring of landslide slope movements, soil electrical conductivity or water content measurement in soil [6]. Next development of TDR technology started in order to meet requirements for reliable, low cost, easy installed and remote sensing possibility [7].

TDR technology works on principle of radar in coaxial cable, where an electric voltage is pulsing and signal is reflected from the point where inconsistency of electrical properties occurs. It means zone of deformation, shearing zone, tensile zone, where change in dielectric constant is present. Many types of coaxial cables can be used but not every type is suitable for inclinometers. Important is grout applied around the cable, which must have a stiffness similar to rock environment in addition to create deformation of cable in early time of slope mass movement and another function is fixing the cable in stable part of slope. Generally, installation in landslide body is ideal when inclinometer across slide zone in perpendicular direction. This can guarantee that when landslide is active the coaxial cable is deformed, altering the distance between inner and outer conductor of the cable. Signal travel time, hence time domain, and known propagation velocity determine localization of signal reflection. The analysis of the reflected signal can reveal information about the type and intensity of deformation; see Fig. 1.

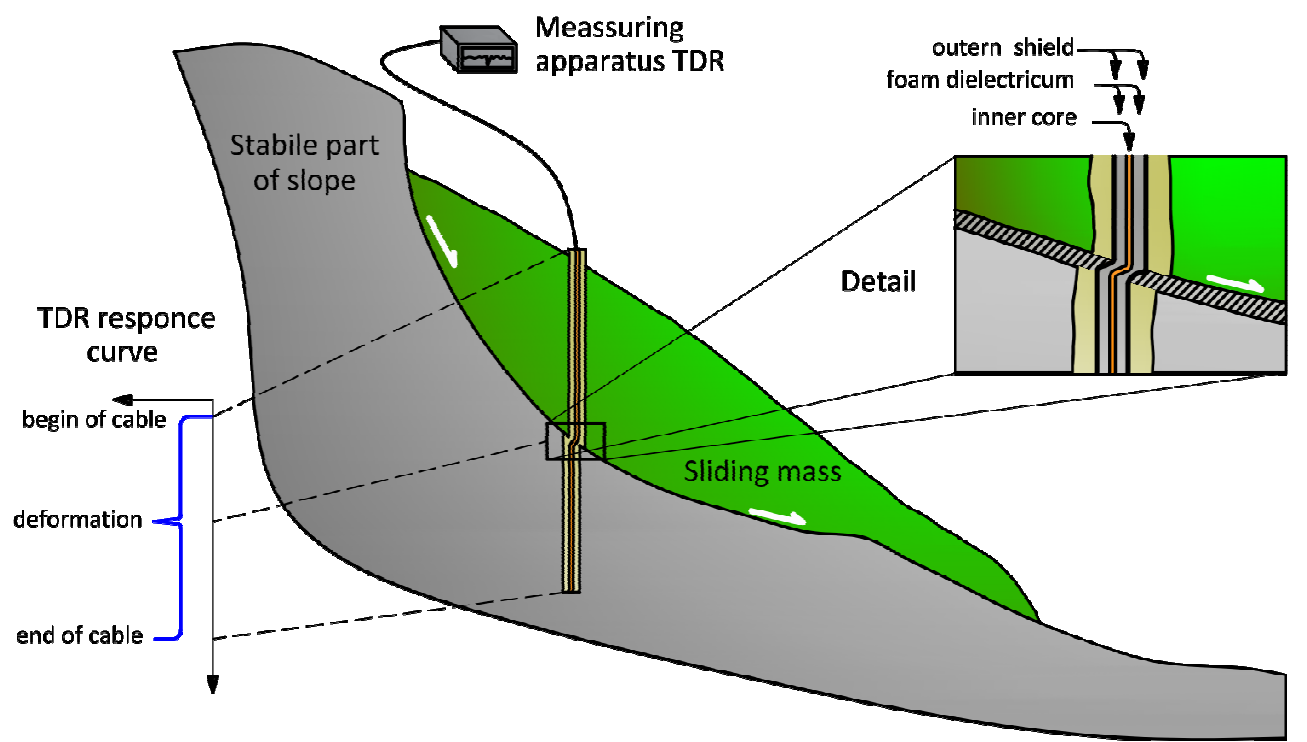

Fig. 1: Principle of TDR inclinometer measurement, $[2,8]$.

One of the disadvantages of TDR technology is not direct deformation measuring, but it can be observed progress of deformation through the amplitude of reflection coefficient $\rho_{\rho},[1,2,9]$. It is defined as a ratio of reflected voltage $V_{r}$ to incident voltage $V_{i}$

$\rho_{r}=\frac{V_{r}}{V_{i}}$.

To develop dependence of reflection coefficient $\rho_{r}$ on exact value of cable deformation $\Delta \mathrm{x}$ at place of shearing, laboratory calibration of cable and grout in simple equipment was done; see Fig. 2 , [8]. Testing coaxial cable had been installed horizontally on three segments of "U" profile and grouted by cement bentonite suspension. After 28 days of grout hardening, shearing simulation process 
started by pressure of two hydraulic jacks and exact values of deformation was measured by precise micrometres devices.

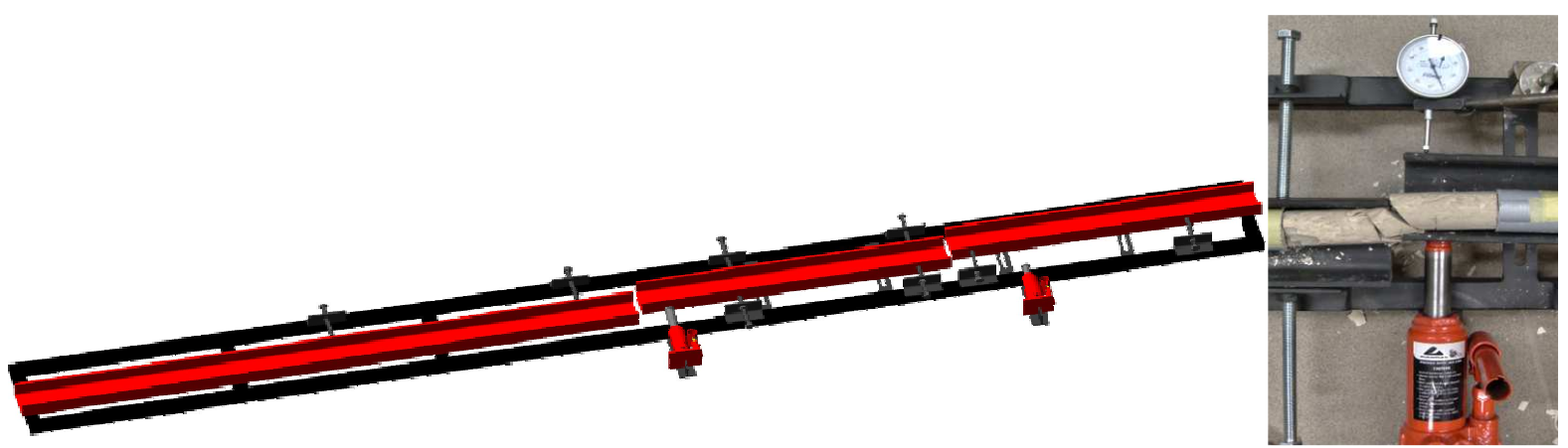

Fig. 2: The laboratory device for calibration of TDR measurement (left), detail of calibration process (right), [8].

The cable signature, or plot of $\rho_{r}$ versus depth, represents the amount of energy reflected at a given distance $z[\mathrm{~m}]$ from the source of the pulse analysed at a given instant in time, hence the term Time Domain Reflectometry, [7].

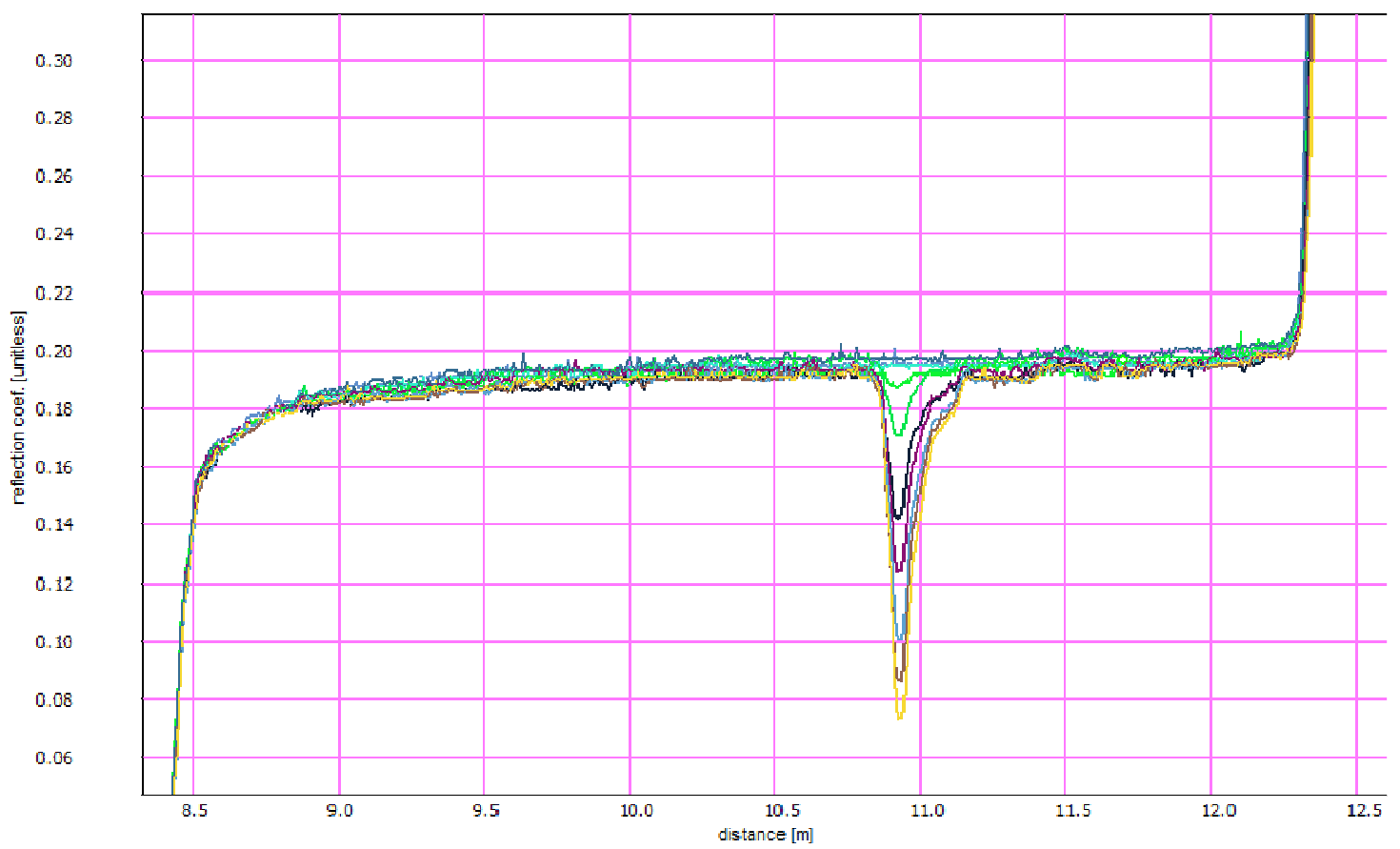

Fig. 3: Amplitude rising of reflection coefficient [millirhos] in the zone of deformation [m].

For every created deformation by hydraulic jack in laboratory device (Fig. 2) a group of reflection coefficient curves was recorded, Fig. 3. The rigid shear plane simulation allowed to record deformation up to $45 \mathrm{~mm}$ and results are plotted on graph of Fig. 4. Observed dependence of reflection coefficient and value of deformation $\Delta \mathrm{x}$ is correlated through the $2^{\text {nd }}$ order of polynomial regression, eq. (2), [2, 8]

$\Delta \mathrm{x}=-42419 \rho_{r}{ }^{3}+16476 \rho_{r}{ }^{2}-2295.20 \rho_{r}+141.94 \quad[\mathrm{~mm}]$,

where $\rho_{r}$ is reflection coefficient measured in millirhos unit, defined in every place of detection with precision dependant on total length of cable. 


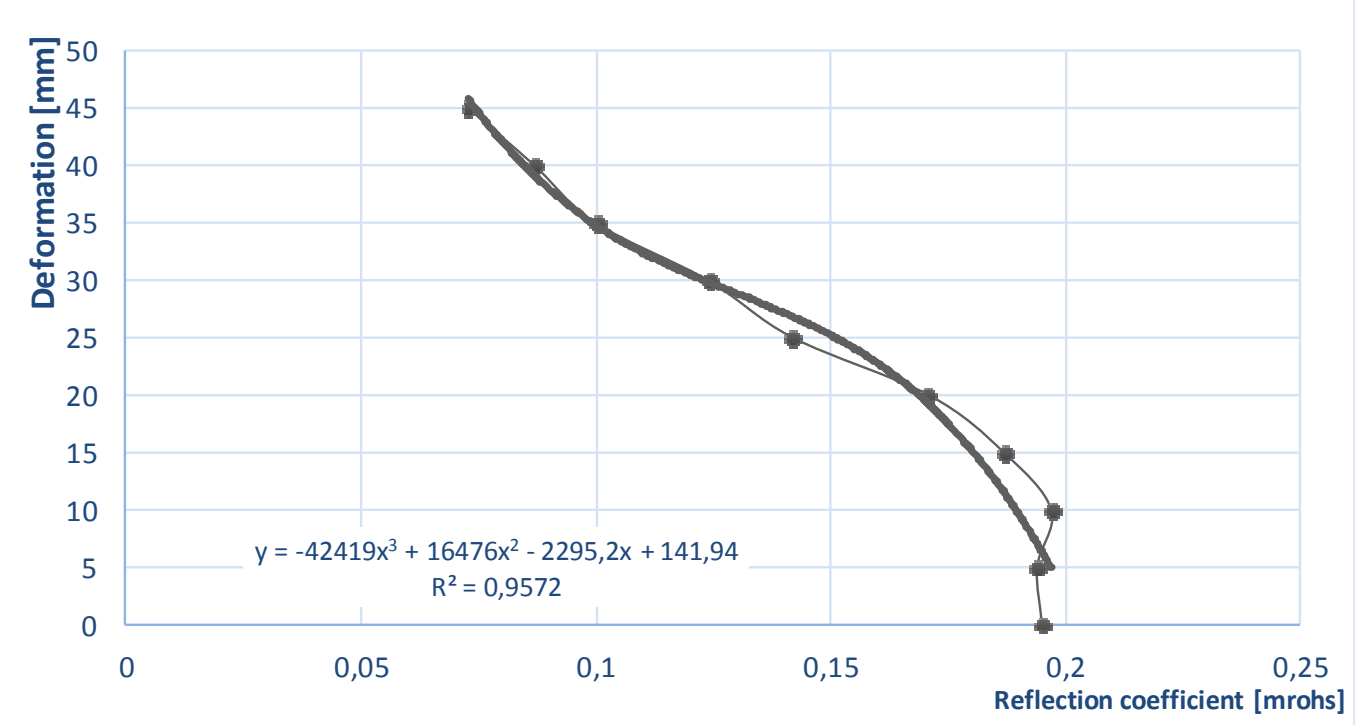

Fig. 4: Correlation of reflection coefficient to deformation $\Delta \mathrm{x}$.

\section{Rockslide characterization}

The massive rockslide between the villages of Šútovo and Kral'ovany in old quarry called Rieka was activated in April 2013, (Fig. 5). Total area of landslide was estimated to be $96,950 \mathrm{~m}^{2}$ and active area to be $59,070 \mathrm{~m}^{2}$. The rockslide has a planar-shaped slip plane in depth of 20 to $40 \mathrm{~m} \mathrm{[10]}$ and cubature in motion exceeded 2,000,000 $\mathrm{m}^{3}$. This area is located close to the construction corridor of highway D1, section Turany - Hubová. National Highway Company as contractor of D1 construction ordered installation of complex geotechnical monitoring including vertical inclinometers, TDR inclinometers, and measurement of groundwater level in affected area. The Department of Geotechnics from the University of Žilina equipped one of the boreholes with coaxial cable for using TDR technology. Installation was performed in February 2014 and till now 6 stages of measurement have been done, Fig. 6 .

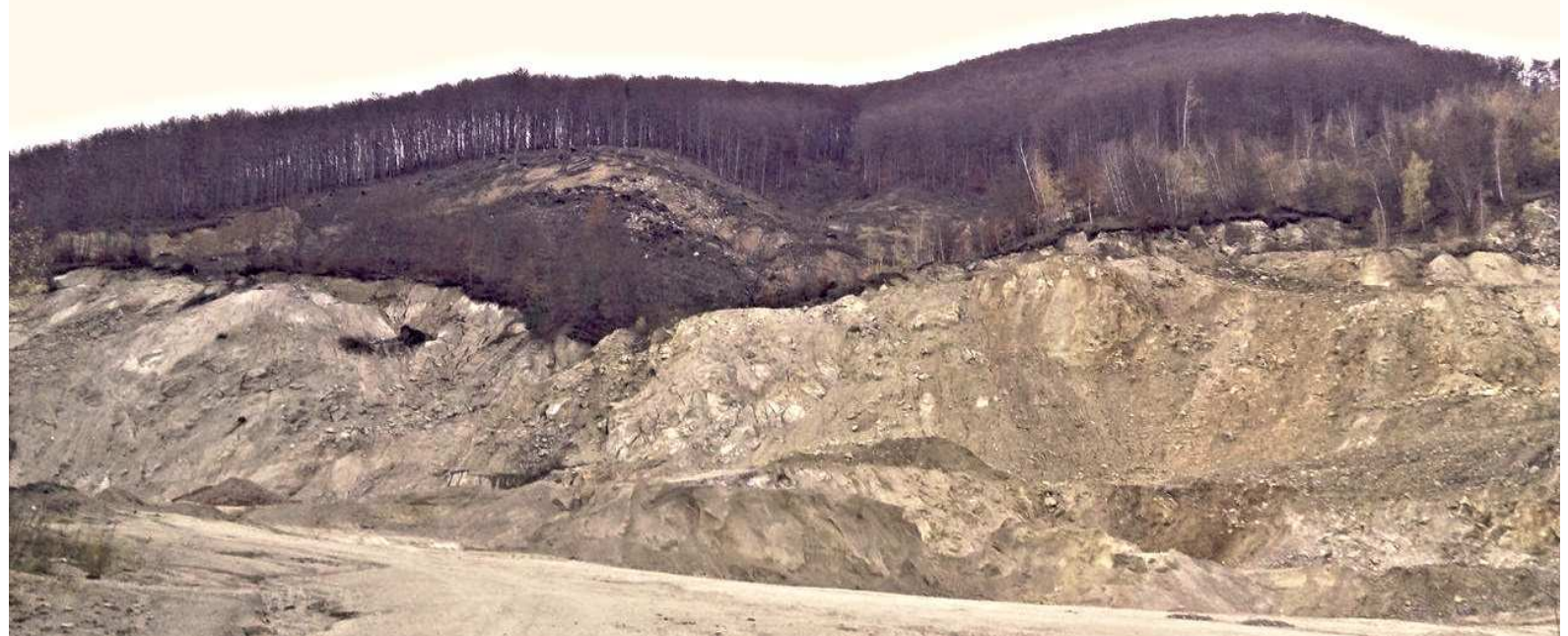

Fig. 5: View of area of active rockslide in 2015. 

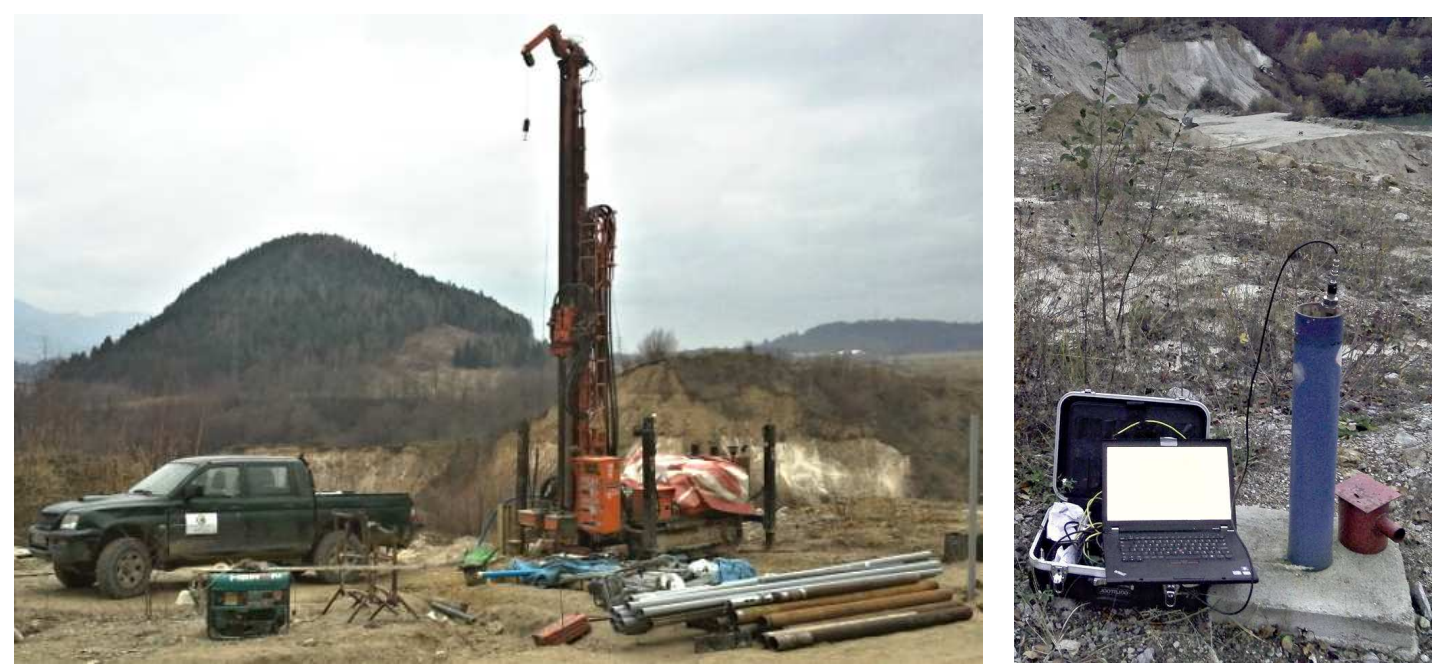

Fig. 6: Borehole drilling and cable installation (left), measurement by TDR apparatus (right).

At present, massive rockslide is moving in two directions. In the main active zone with opened tensile cracks of depth max. $10 \mathrm{~m}$, slope is sliding towards the southwest. This is probably related to predisposition contact between overburden dolomites and deep seated granite bedrock with SW divergence. The entire eastern part of the rockslide is currently located at distance of $60 \mathrm{~m}$ from the current bank line of "Velké jazero". There are various complicated formations in the eastern part of the landslide area, which have not been clearly identified and therefore supplementary survey works have been realized in stage of survey of rockslide and monitoring installation.

Measurements in the newly equipped vertical inclinometers pointed to existence of deep seated slip surface and demonstrated active movement. According to information of local people, landslide was active two times, on March 6 and 21, 2013, [11, 12].

The activity of Sútovský rockslide will cause modification of the D1 motorway route in this direction. Secondly estimated costs for this part of motorway have increased significantly and other variants of route modification and redirection to the preferred direction of the tunnel Korbel'ka have also been announced. The third alternative is routing motorway to a long tunnel "Vel'ká Fatra" situated in south. When comparing all three variants from financial, geological, and technical parameters it is evident that most convenient is to start with the construction of the tunnel Korbel'ka, [12, 13].

\section{Performance of TDR measurements and evaluations}

The initial (zero) phase measurement of rockslide was performed in February 2014, in the legend this stage was titled $0 \_A V \_02 / 2014$, the $1^{\text {st }}$ stage of measurement (1-AV_04/2014) was performed 43 days later on April 11, 2014, the $2^{\text {nd }}$ stage (2-AV_05/2014) was carried out further 82 days later on May 20, 2014. It was determined from those measurements that from given period of time till spring 2014, the rockslide had no significant activity and deformations were small, and this method did not detect those (Figs. 7 - 10). It also means that installation was performed after initial activities. After restarting the measurements in autumn 2015, carried out by the $3^{\text {rd }}$ stage (3$\left.\mathrm{AV} \_10 / 2015\right)$ and followed by the $4^{\text {th }} ; 5^{\text {th }}$, and $6^{\text {th }}$ stage $\left(6-A V \_11 / 2016\right)$, new activity of rockslide in tree depth levels was found, see details on Figs. 8, 9, and 10. 


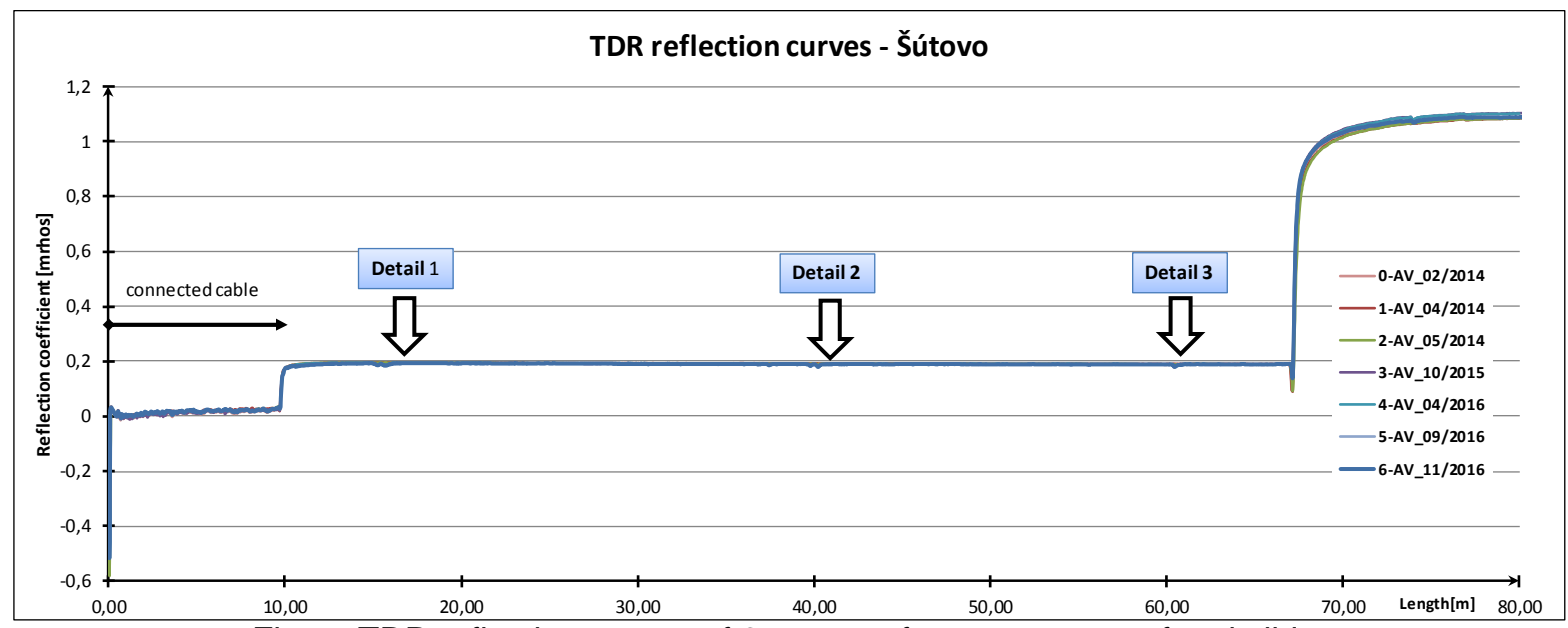

Fig. 7: TDR reflection curves of 6 stages of measurement of rockslide.

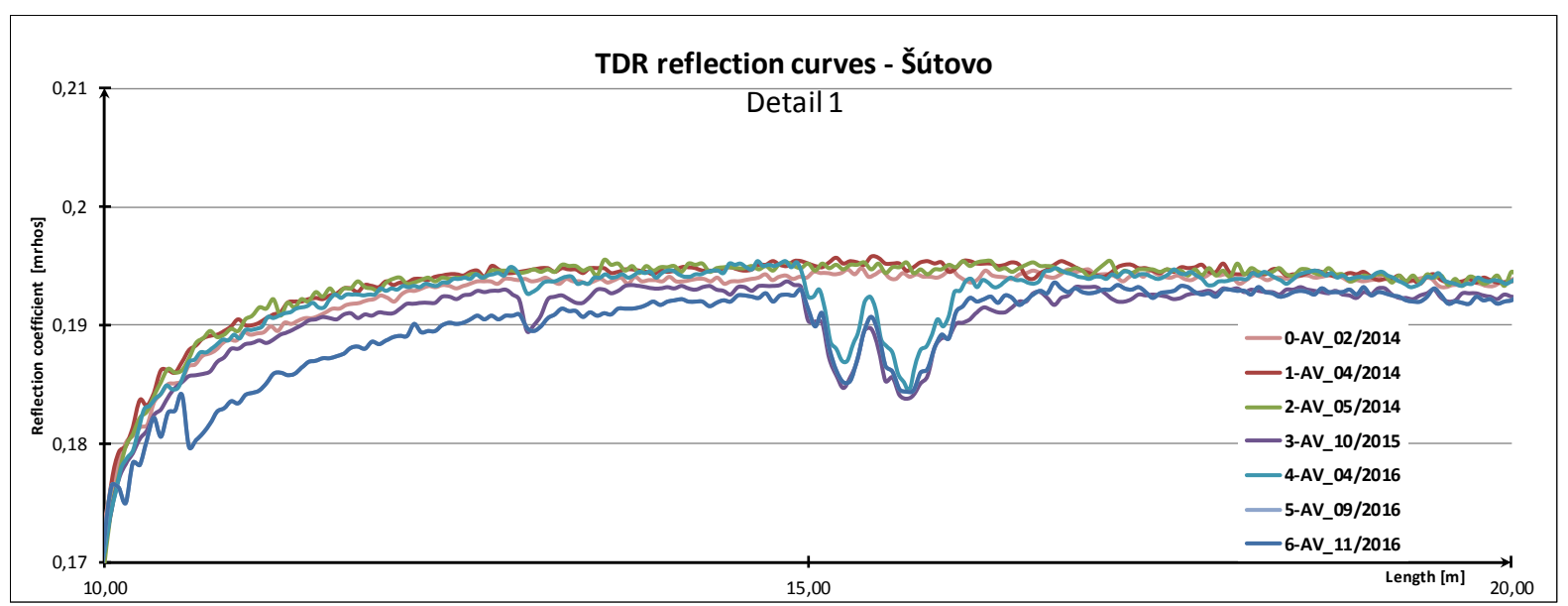

Fig. 8: Detail 1 of reflection curves.

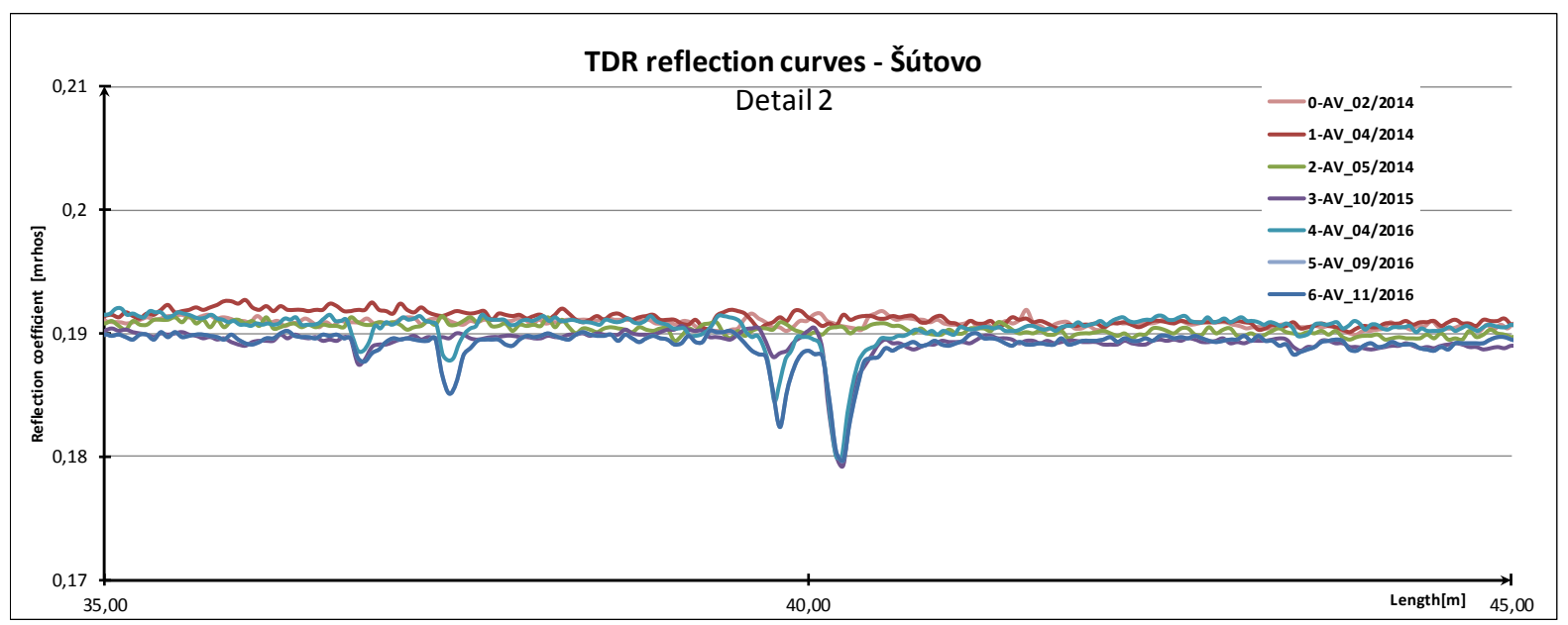

Fig. 9: Detail 2 of reflection curves. 


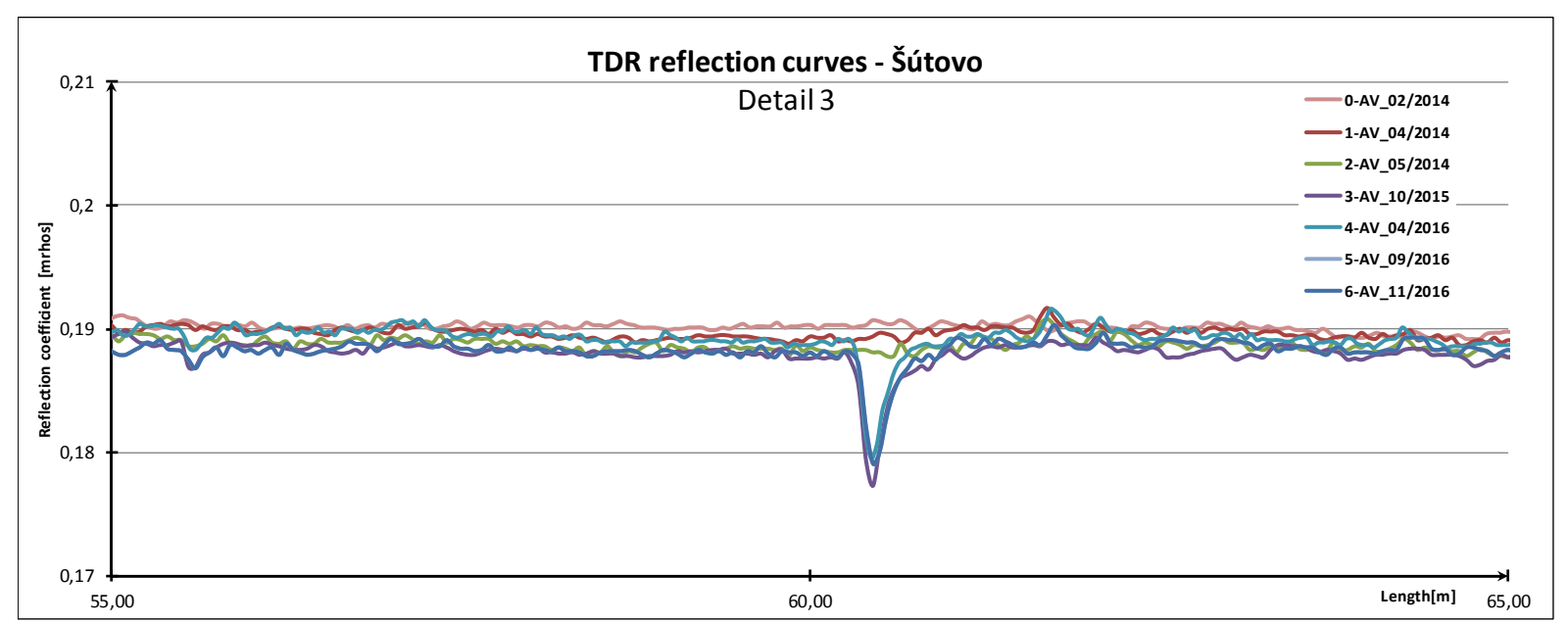

Fig. 10: Detail 3 of reflection curves.

After subtracting the power cord length of connected apparatus from the total length and extrapolation to the actual length, it has been discovered that the shear planes are in the depth 4.95, 27, and $45.5 \mathrm{~m}$ below surface. Estimated horizontal deformations are in interval $20-30 \mathrm{~mm}$, which means that workability of TDR inclinometers is in middle part of functionality. The slip surfaces were confirmed by other measurements in November 2016, and their positions remained unchanged till last measurement. It means that rockslide was active in short time intervals, when active forces across equilibrium conditions. Detection of tree slip surfaces helps to explain the complicated model of rockslide and confirm the ability of TDR technology to detect more zones of deformation.

\section{Conclusions}

The construction of the new route of motorway D1 from Bratislava to Košice, which is the backbone for transport infrastructure of Slovakia, enters its final part Turany - Hubová. In this section a massive rockslide has been activated in a quarry close to the main road of first class $1 / 18$ near the village of Sútovo. To better assess possible alternatives, it is necessary to monitor activated rockslide, which can endanger route of first class but also of main railway line from east to west part of Slovakia. Vertical inclinometers, piezometers, and TDR inclinometer were installed in February 2014 by Department of Geotechnics of the University of Žilina. It has been performed six stages of measurements. First and second stage detected small deformation, no significant movement. The third stage of measurement from October 2015 showed underground movement activity, which can be interpreted according to the acquired waveforms reflection coefficient. A continual control measurement in 2016 confirmed the development of shear deformation from 2015. TDR inclinometer recorded tree slip surfaces, first at a depth of $4.95 \mathrm{~m}$, second at a depth of $27 \mathrm{~m}$, and third at a depth of $45.5 \mathrm{~m}$ below the surface. The monitoring will continue at regular intervals to determine the seriousness and development of deformations in time for the further strategic decision of the whole project D1 motorway. Although the technology TDR does not measure the exact deformation, its advantages lie in rapid installation, ease of remote sensing, multiple progress detection until cable breakout, ground water detection, and very precise detection of shear zones, [2, 7].

\section{References}

[1] DOWDING, C. H. - O'CONNOR, K. M.: Geomeasurements by Pulsing TDR Cables and Probes. Boca Raton: CRC Press, 1999, ISBN 08-493-0586-1.

[2] DRUSA, M. - CHEBEŇ, V.: Geotechnical Monitoring of Road Embankment in Landslide Area by Time Domain Reflectometry Technology. In: Proceedings of 11th International Multidisciplinary Scientific Geo-Conference \& Expo, Sgem 2011, Albena 20 - 25, June 2011, ISSN 1314-2704.

[3] SEGALINI, A. - CARINI, C.: Underground Landslide Displacement Monitoring: A New MMES Based Device. In: Landslide Science and Practice, Vol. 2, 2013, Early Warning, Instrumentation and Monitoring - Margottini, Canuti \& Sassa Eds.: Springer London, p. 87 - 93, DOI: 10.1007/9783-642-31445-2. 
[4] SEGALINI, A. - CHIAPPONI, L. - PASTARINI, B.: Application of modular underground monitoring system (MUMS) to landslides monitoring: Evaluation and new insights. In: Engineering Geology for Society and Territory - Volume 2, 2015: Landslide Processes. Springer Int. Publishing, DOI: 10.1007/978-3-319-09057-3.

[5] DECKÝ, M. - DRUSA, M. - PEPUCHA, L'. - ZGÚTOVÁ, K.: Earth Structures of Transport Constructions. Harlow: Essex: Pearson, 2013, p.180, ISBN 978-1-78399-925-5.

[6] SINGER, J.: Development of a continuous monitoring system for instable slopes using Time Domain Reflectometry (TDR). PhD Thesis, Technische Universität München, Munich, Germany, 2010, $189 \mathrm{p}$.

[7] CHEBEŇ, V. - DRUSA, M. - KUBA M.: Int. J. of GEOMATE, Sept. 2015, Japan, Vol. 9, No. 1 (SI. No. 17), p. 1428 - 1433. Geotech., Const. Mat. and Env., ISSN 2186-2982(P), p. 2186 - 2990(O).

[8] STOLARIK, L.: Geotechnical monitoring of landslide areas by TDR technology. Diploma thesis, University of Žilina, FCE, 2013

[9] SARGAND, S. M. - SARGENT, L. - FARRINGTON, S. P.: Inclinometer-Time Domain Reflectometry Comparative Study, Final Report December 2004. Athens: Ohio University, 2004.

[10]ŠIMEKOVÁ et al.: Monitoring of the rockslide kinematics in the Kral'ovany Village, Geological studies, Report 122, p. 7 - 27 (in Slovak). Slovak State Geological Institute of Dionýz Štúr Bratislava, 2013, ISSN 0433-4795.

[11]GRENČíKOVÁ, A. - GAŽÚR, J.: Motorway D1 Turany - Hubová, „Kral'oviansky landslide, Geotechnical monitoring $2^{\text {nd }}$ stage, GEOFOS, Ltd., Žilina, May 2011.

[12]BULKO, R. - DRUSA, M. - MASAROVIČOVÁ, S. - SITÁNYIOVÁ, D.: Monitoring of Slope Deformations in Sútovo by Using TDR Technology. In: Proceedings of the $8^{\text {th }}$ Slovak Conference of Geo - Engineering, Vysoké Tatry, 16 - 17 June, 2016, ISBN 978-80-227-4573-4.

[13] http://www.ndsas.sk/aktuality-zosuv-pri-sutove-moze-sposobit-komplikacie/44372s45470c, online: June 2016 